\title{
Residual Activity of Fludioxonil and Pyrimethanil Against Penicillium expansum on Apple Fruit
}

\author{
C. L. Xiao and R. J. Boal, Department of Plant Pathology, Washington State University, Tree Fruit Research and \\ Extension Center, 1100 N. Western Avenue, Wenatchee, WA 98801
}

\begin{abstract}
Xiao, C. L., and Boal, R. J. 2009. Residual activity of fludioxonil and pyrimethanil against Penicillium expansum on apple fruit. Plant Dis. 93:1003-1008.

Blue mold caused by Penicillium expansum is a major postharvest disease of apples (Malus $\times$ domestica). Residual activity of fludioxonil and pyrimethanil in apple fruit against $P$. expansum was investigated during 2005 to 2008 . Fruit of the cultivar Delicious harvested from commercial orchards where fungicides were not used were either not treated or drenched with fludioxonil, pyrimethanil, or thiabendazole prior to storage and then stored in controlled atmosphere at $0^{\circ} \mathrm{C}$ for 5 or 7 months, after which time the fruit were removed from storage and subjected to washing and brushing, practices that are done at the time of packing. Fruit were then wounded and inoculated with conidial suspensions of $P$. expansum. Inoculated fruit were treated with either sterile water or fungicides. Fruit were stored at $0^{\circ} \mathrm{C}$ for 8 weeks and at room temperature for one additional week after cold storage. To determine distribution of fungicide residues in the fruit flesh, fruit were cut horizontally at the equator, sprayed with the conidial suspension of $P$. expansum, incubated at room temperature, and examined for inhibition of blue mold on the cut fruit 4 days after inoculation. Fungicide residues on/in the fruit were analyzed using a gas chromatograph. Zero to $26 \%$ blue mold incidence was observed on fludioxonil-drenched fruit that were inoculated and not treated with fungicides at packing. No decay or $<4 \%$ blue mold incidence was observed on pyrimethanil-drenched fruit that were inoculated and not treated with fungicides at packing, whereas 65 to $99 \%$ blue mold incidence was observed on thiabendazoledrenched fruit that were not treated with fungicides at packing. An average of $>32 \mathrm{~mm}$ inhibition zone and approximately $5 \mathrm{~mm}$ inhibition zone measured from the fruit peel toward the fruit core were observed on pyrimethanil-drenched and fludioxonil-drenched fruit, respectively. Washing and brushing at the time of packing 5 and 7 months after harvest did not remove or only partially removed residues of fludioxonil and pyrimethanil from apple fruit. The results suggest that residues of fludioxonil and pyrimethanil on/in apple fruit are persistent and that residual protection of apple fruit by the two fungicides can last for at least 7 months under apple-storage conditions.
\end{abstract}

At harvest, apple fruit are placed into wooden or plastic bins (approximately 400 $\mathrm{kg}$ of fruit per bin), which are then transported to storage and packing facilities. Prior to storage, fruit may be drenched with a fungicide to control postharvest diseases (10). Fruit are stored in the bins in either regular atmosphere (RA) or controlled atmosphere (CA) (1 to $2 \% \mathrm{O}_{2}$ and $\left.0.5 \% \mathrm{CO}_{2}\right)$ at -1 to $3^{\circ} \mathrm{C}(9)$. Depending on the volume of harvested crops and cultivar, fruit may be stored for up to 10 to 12 months before packing.

Blue mold, caused by Penicillium expansum Link, is a major postharvest fruit rot disease of apple worldwide (11). Punctures, bruises, or any physical damage on the fruit that occur during harvest and postharvest handling are the main avenues for the pathogen to infect apple fruit (11).

Corresponding author: C. L. Xiao

E-mail: clxiao@wsu.edu

Accepted for publication 11 June 2009.

doi:10.1094/PDIS-93-10-1003

(C) 2009 The American Phytopathological Society
Protecting wounds from infections by $P$. expansum is essential to blue mold control. Fungicide applications after harvest are commonly used to control blue mold on stored apple fruit. Since the introduction into the market in the late 1960 s for postharvest use on pome fruits, thiabendazole (TBZ) has been commonly used for control of postharvest diseases of apple, but resistance to TBZ in $P$. expansum often results in the failure of blue mold control $(5,7)$. In 2004, fludioxonil and pyrimethanil were registered for postharvest use on pome fruits in the United States. Fludioxonil and pyrimethanil belong to phenylpyrrole and anilinopyrimidine classes, respectively. Both fungicides are highly effective in inhibiting conidial germination and germ-tube elongation of $P$. expansum (7). The $P$. expansum populations from apple in Washington State prior to the commercial use of these two fungicides consisted of a mixture of phenotypes varying in sensitivity to fludioxonil and pyrimethanil, but both thiabendazolesensitive (TBZ-S) and -resistant (TBZ-R) isolates of $P$. expansum can be effectively controlled by the two new fungicides (7). Currently, fludioxonil and pyrimethanil are increasingly being used as alternatives to TBZ for control of blue mold and other postharvest diseases in pome fruits, and particularly as a tool for control of blue mold caused by TBZ-R strains of $P$. expan$\operatorname{sum}(5,7)$.

The three apple-postharvest fungicides can be applied as either a prestorage drench treatment or a line-spray or dip treatment at packing. Fludioxonil and pyrimethanil are highly effective in controlling blue mold when used as a prestorage drench treatment $(5,7)$. However, it is unknown how long the residues of the two new postharvest fungicides on/in apple fruit can last during cold storage and whether or not the residues of these two fungicides on/in fruit can protect fruit at packing from infection by $P$. expansum, which is commonly present in the water system and on the packingline equipment during packing (14).

The objectives of this study were to determine residual activity of fludioxonil and pyrimethanil in fungicide-drenched apple fruit against $P$. expansum and the distribution of fludioxonil and pyrimethanil residues in the flesh of apple fruit at levels that are effective in inhibiting blue mold development.

\section{MATERIALS AND METHODS}

Fungicides and pathogen isolates. The formulated fungicides thiabendazole (Mertect 340F; Syngenta Crop Protection, Greensboro, NC), fludioxonil (Scholar 50WP or Scholar SC; Syngenta), and pyrimethanil (Penbotec 400SC; Janssen Pharmaceutica N.V., Belgium) were used in this study.

Two isolates (CLX3294 and CLX3354) of $P$. expansum recovered from decayed apple fruit collected from commercial fruit packinghouses were used in this study. CLX3294 is resistant to TBZ and CLX3354 is sensitive to TBZ (8). Conidial suspensions (approximately $1 \times 10^{4} \mathrm{co}-$ nidia per $\mathrm{ml}$ ) of the pathogen made from 7 to 10-day-old potato dextrose agar (PDA; Difco Laboratories, Detroit, MI) cultures grown at $20^{\circ} \mathrm{C}$ were used as inoculum for fruit inoculation.

Postharvest drench with fungicides and storage of fruit. We used apple fruit (Malus $\times$ domestica $)$ cv. Delicious obtained from commercial orchards where fungicides were not used to avoid potential interference by preharvest fungicide residues on the fruit. Fruit were transported to 
the packinghouse facility on the day of harvest.

The experiment was conducted in the 2005-2006, 2006-2007, and 2007-2008 seasons. The fruit from the first two seasons were used to determine residual activity of the fungicides in apple fruit. The fruit from 2006-2007 and 2007-2008 were used to determine the distribution of fungicide residues in the fruit flesh. In all three seasons, fruit were drenched on the day of harvest. Pyrimethanil was applied as Penbotec $400 \mathrm{SC}$ at $1.25 \mathrm{ml} / \mathrm{liter}$, and thiabendazole was applied as Mertect 340F at 1.25 $\mathrm{ml} /$ liter for all three seasons. Fludioxonil was applied as Scholar 50WP at $0.6 \mathrm{~g} / \mathrm{liter}$ in 2005-2006 and as Scholar SC at 1.25 $\mathrm{ml} /$ liter (equivalent to Scholar 50WP at 0.6 $\mathrm{g} / \mathrm{liter}$ ) and $0.94 \mathrm{ml} / \mathrm{liter}$ in 2006-2007 and 2007-2008, respectively. The changes in formulations and rates of Scholar were based on suggested label rates by the manufacturer. Fruit were drenched using a 1,935-liter-tank drencher comparable to commercial operations. The travel time of bins through the drencher was approximately $2.5 \mathrm{~min}$. The drencher was thoroughly rinsed with water between fungicide treatments. Fruit remained in the bins and were drained after drenching. Fruit were then stored in $\mathrm{CA}\left(0^{\circ} \mathrm{C},<1 \% \mathrm{CO}_{2}\right.$, and $1.5 \% \mathrm{O}_{2}$ ).

Handling and inoculation of fruit and fungicide treatments. Part of the fruit was removed from CA 5 or 7 months after drenching. Fruit were subjected to the washing and packing process using a research packingline comparable to commercial operations. Fruit were placed in a $100 \mathrm{ppm}$ sodium hypochlorite solution for 2 min to mimic a common practice for commercial packing in which fruit are first floated through a dump tank filled with a sodium hypochlorite solution. The treated fruit were then manually placed on packingline rollers where they were elevated from the dump tank and passed under a soap bar dispensing Real Clean (containing sodium lauryl ether sulfate, sodium hydroxide, and gluconic acid) ( $\mathrm{CH} 2 \mathrm{O}$, Inc., Olympia, WA) at $160 \mathrm{ml} / 20$ liters of tap water, then a rinse bar with warm tap water. Fruit then ran through a brush conveyor bed. The total time of fruit on the brush bed was approximately $2 \mathrm{~min}$. Fruit then passed through a fruit dryer before exiting the packingline. The fruit were transported to the laboratory for further treatments.

Each treatment was applied to four 20fruit replicates. Each fruit was wounded on one side approximately at the equator with a 4-mm-diameter finishing nail head embedded in a cork to $3 \mathrm{~mm}$ in depth in the fruit flesh. Each wound was inoculated by delivering $20 \mu \mathrm{l}$ of the conidial suspensions of $P$. expansum (TBZ-S or TBZ-R strain) with a pipette into the wound. At approximately $30 \mathrm{~min}$ after inoculation, 20 $\mu \mathrm{l}$ of sterile water or one of the three ap- ple-postharvest fungicides (TBZ, fludioxonil, or pyrimethanil) at the same rates described above was pipetted into the wound. Fruit were kept on fruit trays in the laboratory for 10 to $20 \mathrm{~min}$ before they were placed in cardboard apple-boxes. Fruit were stored at $0^{\circ} \mathrm{C}$ in RA for 8 weeks, at which time lesion size on each fruit was measured. Incidence of blue mold (\% of fruit with blue mold within each replicate of each treatment) was calculated. After cold storage, fruit were stored at room temperature (average $23.8^{\circ} \mathrm{C}$, from 21.7 to $24.8^{\circ} \mathrm{C}$ ) for one additional week, after which decay was evaluated again as described above.

Distribution of effective residues of fungicides in apple fruit. A bioassay was developed to assess the distribution of fungicide residues in the fruit flesh at levels that are effective in inhibiting blue mold development in apple fruit flesh. Fruit stored in CA for 7 months in 20062007 and for 5 and 7 months in 2007-2008 were used in this study. Isolates CLX3294 and CLX3354 were used for the cut fruit assays conducted in 2006-2007 and 20072008 , respectively. Fruit were run through the packingline as described above, and 10 replicate fruits from each drench treatment were then randomly selected for the experiment. Each fruit was cut horizontally at approximately the equator and placed in a disposable muffin pan in a plastic container. The surface of the cut fruit was sprayed with the conidial suspensions of $P$. expansum using a 1-liter household sprayer. A single shot of spray (approximately $1 \mathrm{ml}$ ) was applied to each cut surface. A shallow depth of water was added to the container to maintain high relative humidity. The fruit were incubated at room temperature for 4 days, after which time inhibition zone of blue mold on the cut fruit was measured from the peel of the fruit to the edge of blue mold lesion on the flesh of the cut fruit. If no decay developed on the cut fruit, the distance from the fruit peel to the edge of locule (seed cavity) of the fruit was measured. Four separate measurements at two perpendicular directions were taken from each fruit and averaged. The experiment was performed twice at each monitoring time (5 or 7 months after harvest).

Analysis of fungicide residues on/in the fruit. To detect fungicide residues in apple fruit, the fruit were sampled shortly after they had been drenched with fungicides prior to storage, before washing at packing, and after washing and brushing at packing of fruit that were stored for 5 or 7 months after prestorage fungicidedrench treatments. At each sampling time, three replicates, each with eight apple fruit, were selected from each fungicidedrench treatment for residue analysis. Residue analysis of fruit treated with fludioxonil, pyrimethanil, or thiabendazole was performed by the Quality-
Control Laboratory of Pace International LLC (Wapato, WA) using proprietary methods. Each fruit was quartered. One quarter from each fruit within each replicate was selected to make a composite sample and the composite sample was weighed. Quarters of each composite sample were macerated in a solvent using an electric blender. The slurry was centrifuged for $15 \mathrm{~min}$ and aliquots of the supernatant were analyzed using a Hewlett Packard 6890N gas chromatograph with an NPD detector.

Data analysis. Disease incidence was expressed as percentages of decayed fruit in the total inoculated fruit in each replicate of each treatment and transformed with arcsine-square-root transformation prior to statistical analysis. Disease incidence data were analyzed by analysis of variance using PROC GLM of SAS (version 9.1, SAS Institute, Cary, NC), and means were separated by the WallerDuncan $k$-ratio $t$ test at $k$-ratio $=100(P=$ 0.05).

For the cut fruit assays, each experiment was conducted twice. An $F$ test was used to determine if variance of the two experimental runs was homogeneous. The homogeneity of variance test indicated that the data from both runs of each experiment could be pooled $(P>0.05)$, and thus all further analyses were conducted on pooled data. Analysis of variance was performed using SAS PROC GLM to compare the differences in inhibition zone of blue mold on cut fruit that had been drenched with different fungicides prior to storage and to determine whether or not fungicide residues on/in the fruit had changed 5 and 7 months after the fruit were drenched with fungicides. Means were separated by Fisher's protected least significant difference at $P=0.05$. A $t$ test using PROC TTEST of SAS $(P=0.05)$ was performed to compare whether or not the washing process resulted in reduction of fungicide residues on/in fruit.

\section{RESULTS}

Residual activity of fungicides in fruit. In both seasons, fludioxonil and pyrimethanil showed great residual protection of apple fruit from infection by $P$. expansum. On the fruit that were drenched with fludioxonil prior to storage and inoculated with $P$. expansum but not treated with fungicides at packing, the incidence of blue mold ranged from 0 to $7.5 \%$ and 0 to $8.8 \%$ after 8 weeks of storage at $0^{\circ} \mathrm{C}$ for the fruit that had been stored for 5 and 7 months before packing and inoculation, respectively (Tables 1 and 2). The incidence of blue mold ranged from 0 to $26.3 \%$ and 1.3 to $20 \%$ after the fruit had been kept at room temperature for one additional week post the 8 -week cold storage for the fruit that had been stored for 5 and 7 months before packing and inoculation, respectively. 
Virtually no blue mold developed on the fruit that were drenched with pyrimethanil before storage and inoculated with $P$. expansum 5 and 7 months after drenching, except that $<4 \%$ blue mold was observed on the fruit inoculated with $P$. expansum 5 months after drenching in the 2006-2007 season. In comparison with fludioxonil and pyrimethanil, thiabendazole exhibited the least residual activity against $P$. expansum in Delicious fruit. On the fruit drenched with thiabendazole before storage and inoculated with $P$. expansum 5 or 7 months after drenching, 86.3 to $98.8 \%$ and 43.8 to $98.8 \%$ of the fruit had blue mold in 20052006 and 2006-2007 seasons, respectively (Tables 1 and 2).

Regardless of whether a fungicide was applied to the fruit before storage, fruit that were inoculated with either TBZ-R or TBZ-S P. expansum and treated with either fludioxonil or pyrimethanil at packing 5 and 7 months after drenching had virtually no decay after the inoculated fruit had been stored at $0^{\circ} \mathrm{C}$ for 8 weeks and at room temperature for one additional week. As expected, thiabendazole was effective to control the TBZ-S but not the TBZ-R strain of $P$. expansum (Tables 1 and 2).

Distribution of effective residues in the fruit. In the cut-fruit assays, inhibition zone of blue mold was used as an indicator of distribution of effective levels of fungicide residues in the fruit flesh. The results from the bioassays in both years were consistent (Fig. 1). On the cut fruit sprayed with conidial suspensions of $P$. expansum, $100 \%$ of the surface of nondrenched fruit was decayed by blue mold. Little or no inhibition of blue mold was observed on thiabendazole-drenched fruit. In comparison, the vast majority of the cut surface of pyrimethanil-drenched fruit did not develop blue mold, and an average of $>32$ $\mathrm{mm}$ inhibition zone and approximately 5 $\mathrm{mm}$ inhibition zone measured from the fruit peel inward were observed on pyrimethanil-drenched fruit and fludioxonil-drenched fruit, respectively.

Fungicide residues on/in the fruit. In both seasons, residues of all three fungicides on nonwashed fruit remained at similar levels 5 and 7 month after the fruit had been drenched with fungicides (Figs. 2 and 3). After washing at packing, fludioxonil residue in the fruit 5 months after drenching was significantly reduced compared to

Table 1. Residual activity of postharvest fungicides applied as a prestorage drench treatment in Delicious apple fruit against Penicillium expansum with or without fungicides applied at packing for control of blue mold in 2005-2006

\begin{tabular}{|c|c|c|c|c|c|c|c|c|c|}
\hline \multirow{3}{*}{$\begin{array}{l}\text { Drench } \\
\text { treatment } \\
\text { applied prior } \\
\text { to } \text { storage }^{x}\end{array}$} & \multirow{3}{*}{$\begin{array}{l}\text { Treatment at } \\
\text { packing } 5 \\
\text { or } 7 \text { months } \\
\text { postdrench }\end{array}$} & \multicolumn{4}{|c|}{5 Months postdrench treatments } & \multicolumn{4}{|c|}{7 Months postdrench treatments } \\
\hline & & \multicolumn{2}{|c|}{$\begin{array}{c}\text { Blue mold incidence }(\%) \\
8 \text { weeks at } 0^{\circ} \mathrm{C} \\
\text { postpacking }\end{array}$} & \multicolumn{2}{|c|}{$\begin{array}{l}\text { Blue mold incidence }(\%) \\
\text { one addl. week at room } \\
\text { temp. after cold storage }\end{array}$} & \multicolumn{2}{|c|}{$\begin{array}{c}\text { Blue mold incidence }(\%) \\
8 \text { weeks at } 0^{\circ} \mathrm{C} \\
\text { postpacking }\end{array}$} & \multicolumn{2}{|c|}{$\begin{array}{l}\text { Blue mold incidence }(\%) \\
\text { one addl. week at room } \\
\text { temp. after cold storage }\end{array}$} \\
\hline & & TBZ-S $^{\mathbf{y}}$ & TBZ-R & TBZ-S & TBZ-R & TBZ-S & TBZ-R & TBZ-S & TBZ-R \\
\hline \multirow[t]{4}{*}{ Nontreated } & No fungicide & $82.4 b^{z}$ & $100 \mathrm{a}$ & $86.1 \mathrm{~b}$ & $100 \mathrm{a}$ & $86.3 \mathrm{~b}$ & $92.5 \mathrm{~b}$ & $92.5 \mathrm{a}$ & $93.8 \mathrm{a}$ \\
\hline & Fludioxonil & $0 \mathrm{c}$ & $0 \mathrm{f}$ & $0 \mathrm{~d}$ & $0 \mathrm{e}$ & $0 \mathrm{~d}$ & $0 \mathrm{e}$ & $0 \mathrm{~d}$ & $0 \mathrm{~d}$ \\
\hline & Pyrimethanil & $0 \mathrm{c}$ & $0 \mathrm{f}$ & $0 \mathrm{~d}$ & $0 \mathrm{e}$ & $0 \mathrm{~d}$ & $0 \mathrm{e}$ & $0 \mathrm{~d}$ & $0 \mathrm{~d}$ \\
\hline & Thiabendazole & $0 \mathrm{c}$ & $96.3 \mathrm{~b}$ & $0 \mathrm{~d}$ & $98.8 \mathrm{a}$ & $0 \mathrm{~d}$ & $98.8 \mathrm{a}$ & $0 \mathrm{~d}$ & $98.8 \mathrm{a}$ \\
\hline \multirow[t]{3}{*}{ Thiabendazole } & No fungicide & $93.8 \mathrm{a}$ & $87.5 \mathrm{c}$ & $95 \mathrm{a}$ & $92.5 \mathrm{~b}$ & $90 \mathrm{a}$ & $98.8 \mathrm{a}$ & $86.3 \mathrm{~b}$ & $98.8 \mathrm{a}$ \\
\hline & Fludioxonil & $0 \mathrm{c}$ & $0 \mathrm{f}$ & $0 \mathrm{~d}$ & $0 \mathrm{e}$ & $0 \mathrm{~d}$ & $0 \mathrm{e}$ & $0 \mathrm{~d}$ & $1.3 \mathrm{~d}$ \\
\hline & Pyrimethanil & $0 \mathrm{c}$ & $0 \mathrm{f}$ & $0 \mathrm{~d}$ & $0 \mathrm{e}$ & $0 \mathrm{~d}$ & $0 \mathrm{e}$ & $0 \mathrm{~d}$ & $0 \mathrm{~d}$ \\
\hline \multirow[t]{3}{*}{ Fludioxonil } & No fungicide & $1.3 \mathrm{c}$ & $7.5 \mathrm{e}$ & $6.3 \mathrm{c}$ & $26.3 \mathrm{~d}$ & $8.8 \mathrm{c}$ & $2.5 \mathrm{~d}$ & $20 \mathrm{c}$ & $16.3 \mathrm{c}$ \\
\hline & Thiabendazole & $0 \mathrm{c}$ & $27.5 \mathrm{~d}$ & $0 \mathrm{~d}$ & $60 \mathrm{c}$ & $0 \mathrm{~d}$ & $16.3 \mathrm{c}$ & $0 \mathrm{~d}$ & $33.8 \mathrm{~b}$ \\
\hline & Pyrimethanil & $0 \mathrm{c}$ & $0 \mathrm{f}$ & $0 \mathrm{~d}$ & $0 \mathrm{e}$ & $0 \mathrm{~d}$ & $0 \mathrm{e}$ & $0 \mathrm{~d}$ & $1.3 \mathrm{~d}$ \\
\hline \multirow[t]{3}{*}{ Pyrimethanil } & No fungicide & $0 \mathrm{c}$ & $0 \mathrm{f}$ & $0 \mathrm{~d}$ & $0 \mathrm{e}$ & $0 \mathrm{~d}$ & $0 \mathrm{e}$ & $0 \mathrm{~d}$ & $0 \mathrm{~d}$ \\
\hline & Thiabendazole & $0 \mathrm{c}$ & $0 \mathrm{f}$ & $0 \mathrm{~d}$ & $0 \mathrm{e}$ & $0 \mathrm{~d}$ & $0 \mathrm{e}$ & $0 \mathrm{~d}$ & $1.3 \mathrm{~d}$ \\
\hline & Fludioxonil & $0 \mathrm{c}$ & $0 \mathrm{f}$ & $0 \mathrm{~d}$ & $0 \mathrm{e}$ & $0 \mathrm{~d}$ & $0 \mathrm{e}$ & $0 \mathrm{~d}$ & $0 \mathrm{~d}$ \\
\hline
\end{tabular}

${ }^{x}$ Thiabendazole was applied as Mertect $340 \mathrm{~F}$ at $1.25 \mathrm{ml} /$ liter. Pyrimethanil was applied as Penbotec $400 \mathrm{SC}$ at $1.25 \mathrm{ml} /$ liter. Fludioxonil was applied as Scholar 50WP at $0.6 \mathrm{~g} /$ liter in 2005-2006.

y $\mathrm{TBZ}-\mathrm{S}=$ thiabendazole-sensitive isolate, $\mathrm{TBZ}-\mathrm{R}=$ thiabendazole-resistant isolate.

${ }^{\mathrm{z}}$ Values within the same column followed by the same letter are not significantly different according to Waller-Duncan $k$-ratio $t$ test at $k$-ratio $=100(P=0.05)$.

Table 2. Residual activity of postharvest fungicides applied as a prestorage drench treatment in Delicious apple fruit against Penicillium expansum with or without fungicides applied at packing for control of blue mold in 2006-2007

\begin{tabular}{|c|c|c|c|c|c|c|c|c|c|}
\hline \multirow{3}{*}{$\begin{array}{l}\text { Drench } \\
\text { treatment } \\
\text { applied prior } \\
\text { to storage }\end{array}$} & \multirow{3}{*}{$\begin{array}{l}\text { Treatment at } \\
\text { packing } 5 \\
\text { or } 7 \text { months } \\
\text { postdrench }\end{array}$} & \multicolumn{4}{|c|}{5 Months postdrench treatments } & \multicolumn{4}{|c|}{7 Months postdrench treatments } \\
\hline & & \multicolumn{2}{|c|}{$\begin{array}{c}\text { Blue mold incidence }(\%) \\
8 \text { weeks at } 0^{\circ} \mathrm{C} \\
\text { postpacking }\end{array}$} & \multicolumn{2}{|c|}{$\begin{array}{l}\text { Blue mold incidence }(\%) \\
\text { one addl. week at room } \\
\text { temp. after cold storage }\end{array}$} & \multicolumn{2}{|c|}{$\begin{array}{c}\text { Blue mold incidence }(\%) \\
8 \text { weeks at } 0^{\circ} \mathrm{C} \\
\text { postpacking }\end{array}$} & \multicolumn{2}{|c|}{$\begin{array}{l}\text { Blue mold incidence }(\%) \\
\text { one addl. week at room } \\
\text { temp. after cold storage }\end{array}$} \\
\hline & & TBZ-S $\mathbf{S}^{\mathbf{2}}$ & TBZ-R & TBZ-S & TBZ-R & TBZ-S & TBZ-R & TBZ-S & TBZ-R \\
\hline \multirow{4}{*}{ Nontreated } & No fungicide & $100 a^{z}$ & $95 \mathrm{~b}$ & $100 \mathrm{a}$ & $98.8 \mathrm{a}$ & $100 \mathrm{a}$ & $78.8 \mathrm{~b}$ & $100 \mathrm{a}$ & $96.3 \mathrm{~b}$ \\
\hline & Fludioxonil & $0 \mathrm{c}$ & $0 \mathrm{~d}$ & $0 \mathrm{~d}$ & $2.5 \mathrm{~d}$ & $0 \mathrm{c}$ & $0 \mathrm{~d}$ & $0 \mathrm{e}$ & $0 \mathrm{c}$ \\
\hline & Pyrimethanil & $0 \mathrm{c}$ & $0 \mathrm{~d}$ & $0 \mathrm{~d}$ & $0 \mathrm{e}$ & $0 \mathrm{c}$ & $0 \mathrm{~d}$ & $0 \mathrm{e}$ & $0 \mathrm{c}$ \\
\hline & Thiabendazole & $0 \mathrm{c}$ & $100 \mathrm{a}$ & $6.3 \mathrm{c}$ & $100 \mathrm{a}$ & $0 \mathrm{c}$ & $97.5 \mathrm{a}$ & $16.3 \mathrm{c}$ & $100 \mathrm{a}$ \\
\hline \multirow[t]{3}{*}{ Thiabendazole } & No fungicide & $51.3 \mathrm{~b}$ & $43.8 \mathrm{c}$ & $70 \mathrm{~b}$ & $81.3 \mathrm{~b}$ & $45 \mathrm{~b}$ & $46.3 \mathrm{c}$ & $65 \mathrm{~b}$ & $98.8 \mathrm{ab}$ \\
\hline & Fludioxonil & $0 \mathrm{c}$ & $0 \mathrm{~d}$ & $0 \mathrm{~d}$ & $0 \mathrm{e}$ & $0 \mathrm{c}$ & $0 \mathrm{~d}$ & $0 \mathrm{e}$ & $0 \mathrm{c}$ \\
\hline & Pyrimethanil & $0 \mathrm{c}$ & $0 \mathrm{~d}$ & $0 \mathrm{~d}$ & $0 \mathrm{e}$ & $0 \mathrm{c}$ & $0 \mathrm{~d}$ & $0 \mathrm{e}$ & $0 \mathrm{c}$ \\
\hline \multirow[t]{3}{*}{ Fludioxonil } & No fungicide & $0 \mathrm{c}$ & $0 \mathrm{~d}$ & $1.3 \mathrm{~d}$ & $0 \mathrm{e}$ & $0 \mathrm{c}$ & $0 \mathrm{~d}$ & $2.5 \mathrm{~d}$ & $1.3 \mathrm{c}$ \\
\hline & Thiabendazole & $0 \mathrm{c}$ & $0 \mathrm{~d}$ & $0 \mathrm{~d}$ & $7.5 \mathrm{c}$ & $0 \mathrm{c}$ & $0 \mathrm{~d}$ & $0 \mathrm{e}$ & $1.3 \mathrm{c}$ \\
\hline & Pyrimethanil & $0 \mathrm{c}$ & $0 \mathrm{~d}$ & $0 \mathrm{~d}$ & $0 \mathrm{e}$ & $0 \mathrm{c}$ & $0 \mathrm{~d}$ & $0 \mathrm{e}$ & $0 \mathrm{c}$ \\
\hline \multirow{3}{*}{ Pyrimethanil } & No fungicide & $0 \mathrm{c}$ & $1.3 \mathrm{~d}$ & $2.5 \mathrm{~d}$ & $3.8 \mathrm{~d}$ & $0 \mathrm{c}$ & $0 \mathrm{~d}$ & $0 \mathrm{e}$ & $0 \mathrm{c}$ \\
\hline & Thiabendazole & $0 \mathrm{c}$ & $0 \mathrm{~d}$ & $0 \mathrm{~d}$ & $0 \mathrm{e}$ & $0 \mathrm{c}$ & $0 \mathrm{~d}$ & $0 \mathrm{e}$ & $0 \mathrm{c}$ \\
\hline & Fludioxonil & $0 \mathrm{c}$ & $0 \mathrm{~d}$ & $0 \mathrm{~d}$ & $0 \mathrm{e}$ & $0 \mathrm{c}$ & $0 \mathrm{~d}$ & $0 \mathrm{e}$ & $0 \mathrm{c}$ \\
\hline
\end{tabular}

${ }^{\mathrm{x}}$ Thiabendazole was applied as Mertect $340 \mathrm{~F}$ at $1.25 \mathrm{ml} /$ liter. Pyrimethanil was applied as Penbotec $400 \mathrm{SC}$ at $1.25 \mathrm{ml} /$ liter. Fludioxonil was applied as Scholar SC at $1.25 \mathrm{ml} /$ liter in $2006-07$

${ }^{\mathrm{y}}$ TBZ-S $=$ thiabendazole-sensitive isolate, TBZ-R = thiabendazole-resistant isolate.

${ }^{\mathrm{z}}$ Values within the same column followed by the same letter are not significantly different according to Waller-Duncan $k$-ratio $t$ test at $k$-ratio $=100(P=0.05)$. 
that prior to washing. At 7 months after $(P=0.069)$ after washing than before washing in the 2005-2006 season (Fig. 2) but did not differ significantly between before and after washing in the 2006-2007 drenching in the 2006-2007 season, washing did not significantly reduce pyrimethanil residue in/on the fruit. Washing did not significantly reduce thiabendazole residue 7 months after drenching in the 2005-2006 season, but it significantly reduced thiabendazole residue 5 and 7 months after drenching in the 2006-2007 season.

\section{DISCUSSION}

This is the first report to document uptake of fludioxonil and pyrimethanil by apple fruit and persistent residual activity of fludioxonil and pyrimethanil against $P$. expansum in apple fruit during cold storage. The persistence of fludioxonil and pyrimethanil residues in apple fruit over an drenching, fludioxonil residue was lower season (Fig. 3). Except at 5 months after

extended period of time in cold storage has important implications for decay control and fungicide resistance management. Our results indicate that, when applied as a prestorage drench treatment, the residues of fludioxonil and, in particular, pyrimethanil in the fruit can still provide a great level of protection from infection by $P$. expansum several months after harvest, suggesting that if Delicious fruit have been treated with pyrimethanil prior to storage, no additional fungicides are needed at packing to protect fruit from infection by $P$. expansum. The residue of fludioxonil in apple fruit 5 to 7 months after harvest can also provide a good protection of fruit during cold storage, but the residual protection may be reduced to some extent after the fruit have been stored at room temperature. In a study on pear fruit, fludioxonil residues on/in the fruit treated with fludioxonil decrease during 12 days at $17^{\circ} \mathrm{C}$ and $80 \%$ relative humidity (simulated shelf life conditions) (12). In our
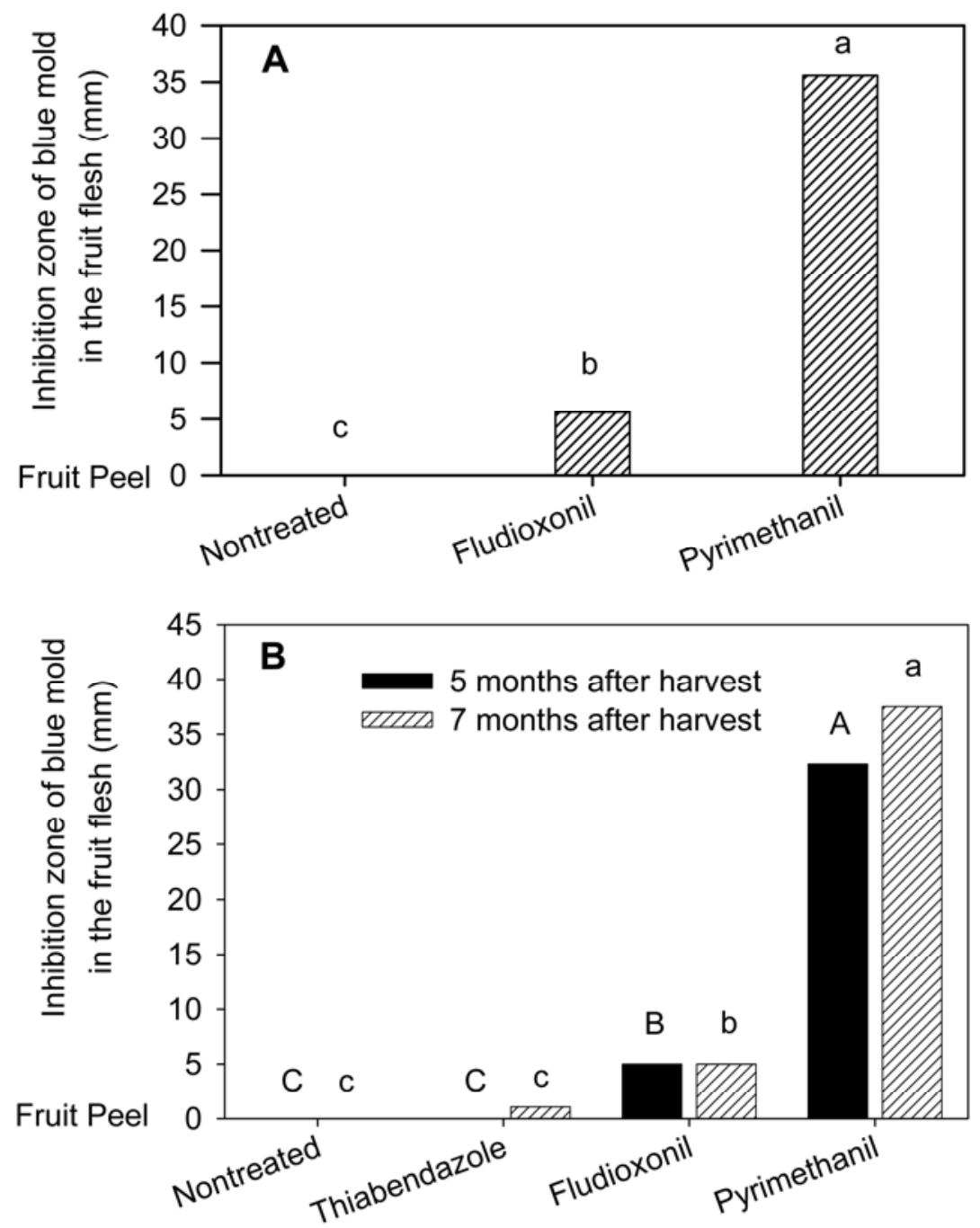

Fig. 1. Distribution of fludioxonil, pyrimethanil, and thiabendazole residues in apple fruit flesh at levels that are effective in inhibiting blue mold caused by Penicillium expansum in 2006-2007 (A) and 2007-2008 (B). Fruit were cut horizontally at the equator. The surface of the cut fruit was sprayed with the conidial suspension of $P$. expansum. Inhibition of blue mold was measured from the fruit peel toward the fruit core. Columns marked with the same letter are not significantly different at $P=0.05$ according to Fisher's protected least significant difference. study, we did not monitor fungicide residues after the fruit had been stored at room temperature for one additional week after cold storage. The decline in residual activity of fludioxonil may be due to decrease in fludioxonil residues in the fruit at room temperature as observed on pear fruit (12).

Persistence of pyrimethanil and fludioxonil in apple fruit under apple-storage conditions also suggests that selection pressure for development of resistance to these fungicides in the $P$. expansum population remains during storage. $P$. expansum is a high-risk pathogen for the development of fungicide resistance because of its short life cycle and prolific reproduction (3). Studies on laboratory-induced pyrimethanil-resistant and fludioxonil-resistant mutants of $P$. expansum indicated that pyrimethanil possesses a higher risk than fludioxonil in the development of resistance in $P$. expansum, partially because there is no fitness cost associated with mutations that confer pyrimethanil resistance, and resistance of $P$. expansum to pyrimethanil is stable. Resistance to pyrimethanil in $P$. expansum is multidrug resistance that extends to fludioxonil and thiabendazole (8). In order to avoid or delay the development of resistance to pyrimethanil, relevant strategies need to be implemented (17). For example, a full label rate should be used to ensure the effectiveness of the fungicide drench treatment. A level of fungicide below the label rate could compromise the efficacy of the fungicide for blue mold control and thus enhance the likelihood of development of fungicide resistance in the pathogen populations because selection pressure for resistance to fludioxonil and pyrimethanil retains for several months during storage. Bins should be sanitized before they are returned to orchards for harvest of the following season crops because contaminated bins can carry fungicide-tolerant strains of $P$. expansum from one crop season to the next (11).

The systemic activity of a fungicide depends on its uptake and subsequent translocation within the plant (13). In our study, residual activity against $P$. expansum and the distribution of effective residues of fungicides in fruit flesh were conducted after the fruit had been subjected to washing and brushing during packing comparable to commercial operations. Fungicide residue analysis was based on a whole fruit assay. Washing and brushing did not significantly remove pyrimethanil residues, even after the fruit had been stored for 7 months in CA. The results from the bioassays on fungicide residues in fruit flesh clearly indicate that pyrimethanil is able to move within the fruit flesh to the seed cavity area and that residues of pyrimethanil in apple fruit flesh can last for several months under conditions commercially used for storage of apples, explaining why pyrimethanil residue was not significantly 
removed by washing and brushing. Persistence of pyrimethanil residues has also been observed on other fruit crops $(1,2)$. Angioni et al. (2) reported that residues of pyrimethanil in strawberries cannot be removed by home tap water washing. These results indicate that pyrimethanil has some level of systemic activity in these fruit crops, at least in apple fruit as we documented in this study.

In comparison, although uptake of fludioxonil by apple fruit was evident in the bioassays in our study, it appeared that fludioxonil residues at the levels effective in inhibiting blue mold development in apple fruit were distributed within approximately $5 \mathrm{~mm}$ underneath the fruit cuticle. Punctures or other types of physical wounds on commercially harvested apple fruit are generally shallow in depth, explaining why infections of such wounds by $P$. expansum were greatly inhibited on fludioxonil-drenched fruit because of the presence of fludioxonil in the fruit flesh underneath the fruit peel. We did not take additional fruit-flesh samples from near the core area of the fruit to analyze whether fludioxonil residues can move farther to the core area of the fruit. Thus, it is still not known whether fludioxonil can translocate as does pyrimethanil to a great extent within the apple fruit flesh. Nevertheless, our results suggest that fludioxonil may have a relatively local systemic activity in apple fruit.

The residual activity of fludioxonil was greater on the drenched fruit in 2005-2006 than in 2006-2007. It is unknown what factors were responsible for the differences. The only apparent difference in the experiments between these two seasons was that different formulations of fludioxonil were used because of the change in formulation implemented by the manufacturer. A wettable powder (WP) formulation was used in 2005-2006 and a spray concentrate (SC) formulation was used in 2006-2007. We did not further test whether there are differences in uptake of fludioxonil by apple fruit between the two formulations of this fungicide.

In our study, the inhibition zone of blue mold in the fruit flesh in the cut fruit assay can only be used as an indicator of the distribution of fungicide residues in the fruit flesh at levels effective in inhibiting blue mold development. The actual levels of fungicide residues on/in the fruit in our study were detected based on a whole fruit assay. We did not further quantify actual levels of fungicide residues in fruit flesh at different distances from the peel. It is possible that the residues of pyrimethanil in fruit flesh within several millimeters underneath the cuticle (peel) of the fruit may be higher than those in the flesh near the fruit seed cavity area, similar to what we observed on fludioxonil-drenched fruit. The uptake of fludioxonil and pyrimethanil by apple fruit and persistence of these two fungicides on drenched fruit may also explain why washing and brushing did not remove or only partially removed residues of pyrimethanil and fludioxonil from apple fruit.

Although we observed that residues of fludioxonil and pyrimethanil on/in apple fruit can persist for several months under apple-storage conditions, the residues of these two fungicides in apple fruit were below the maximum residue levels (MRL) for these two fungicides ( $5 \mathrm{ppm}$ for fludioxonil and $14 \mathrm{ppm}$ for pyrimethanil) approved by the U.S. Environmental Protec- tion Agency (16). The persistence of pyrimethanil and fludioxonil in washed apple fruit may also suggest that in order to limit residues of these two fungicides on/in the fruit not exceeding MRLs, one fungicide should not be used as both a drench treatment applied prior to storage and a line-spray or dip treatment applied at packing onto the same fruit. Using one fungicide as a prestorage drench treatment and another fungicide as an in-line treatment at packing would be a good fungicide-alternation approach for disease control and management of fungicide

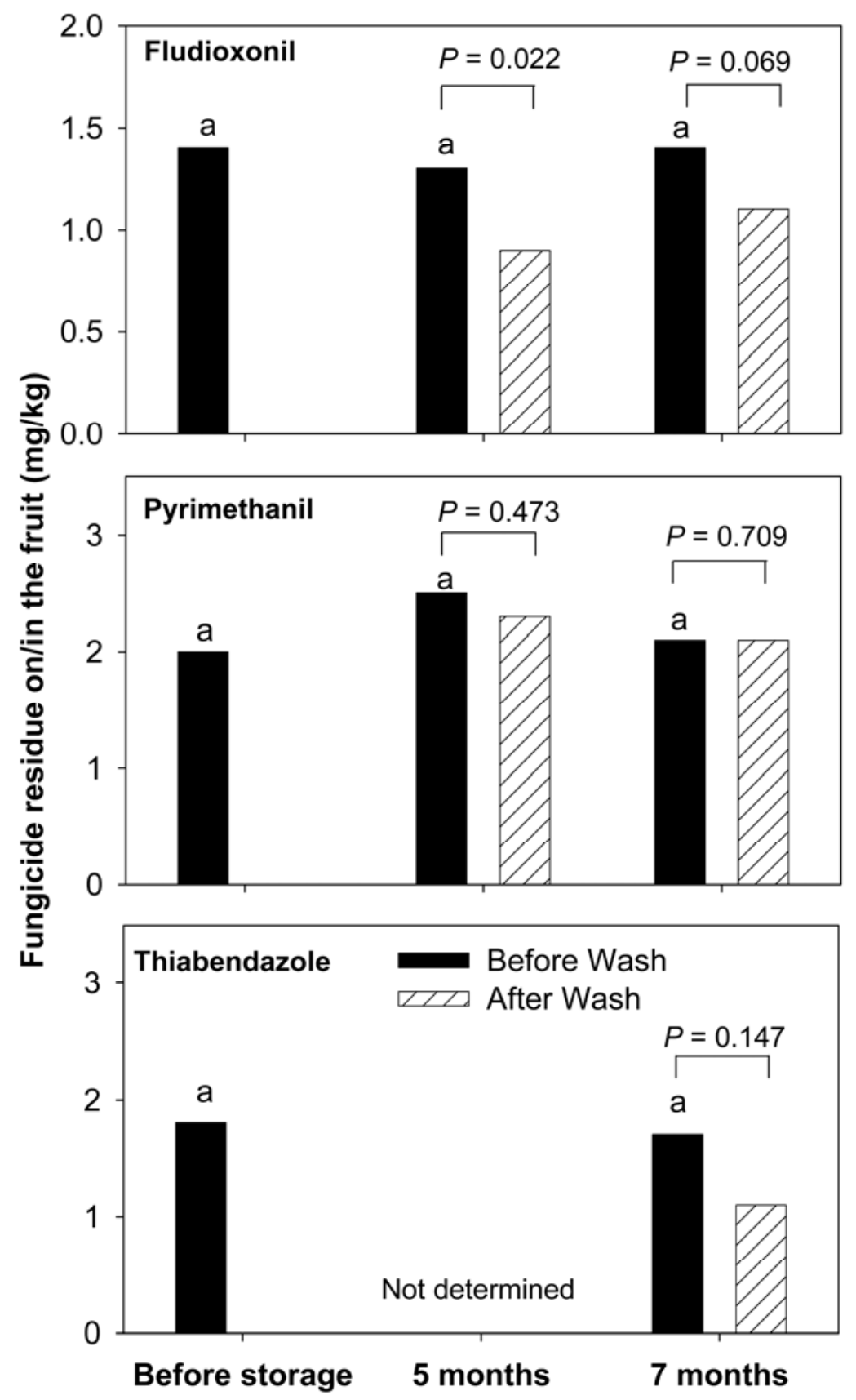

Fig. 2. Residues of fludioxonil, pyrimethanil, or thiabendazole in Delicious apple fruit drenched with the fungicides prior to storage in 2005-2006. Fruit were sampled for residue analysis immediately after drenching and before and after washing at packing 5 or 7 months after harvest. Columns marked with the same letter are not significantly different at $P=0.05$ according to Fisher's protected least significant difference. $P$ values indicate significant levels of reduction in fungicide residues on/in the fruit resulting from washing and brushing at packing according to a $t$ test. 


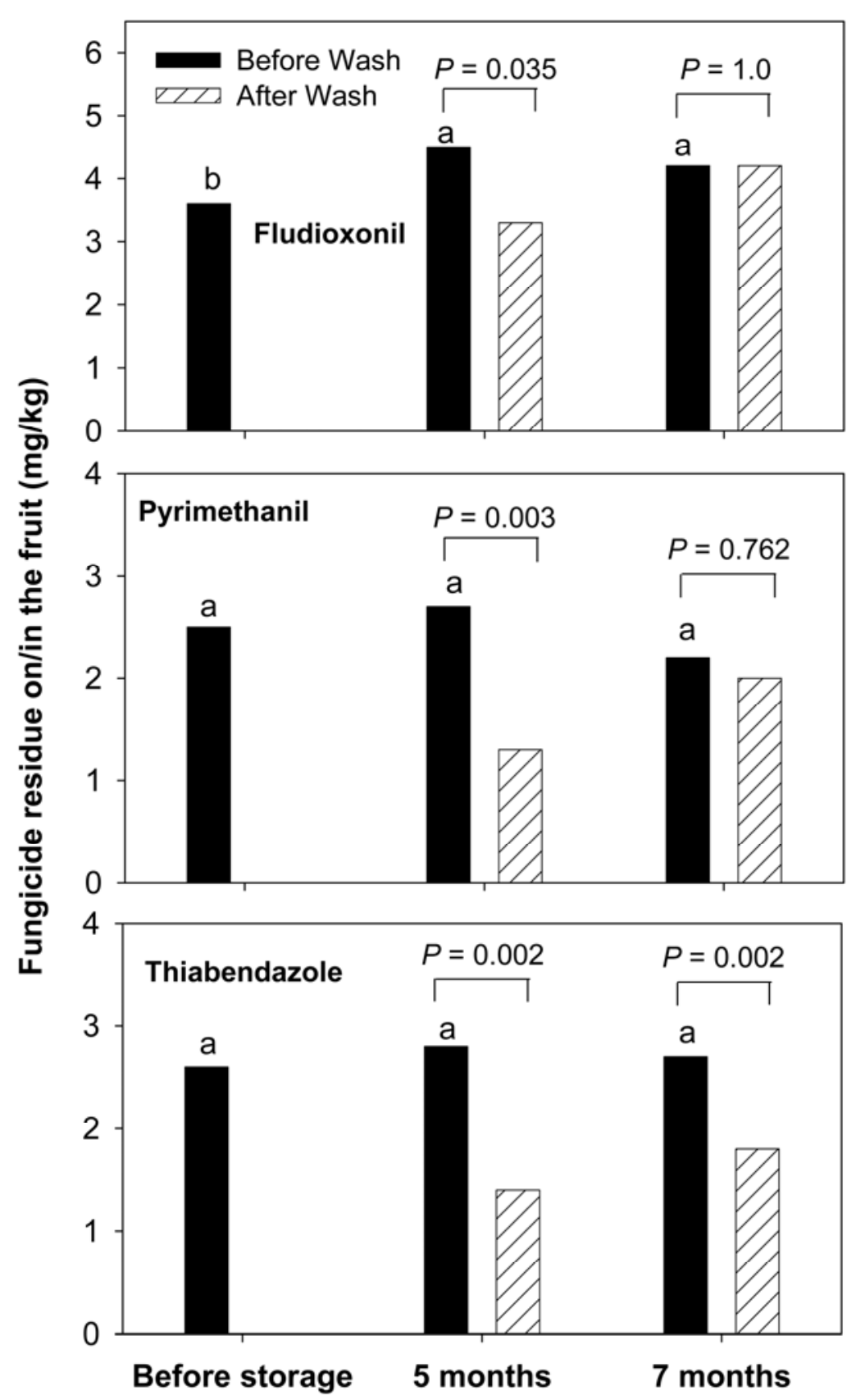

Fig. 3. Residues of fludioxonil, pyrimethanil, or thiabendazole in Delicious apple fruit drenched with the fungicides prior to storage in 2006-2007. Fruit were sampled for residue analysis immediately after drenching and before and after washing at packing 5 or 7 months after harvest. Columns marked with the same letter are not significantly different at $P=0.05$ according to Fisher's protected least significant difference. $P$ values indicate significant levels of reduction in fungicide residues on/in the fruit resulting from washing and brushing at packing according to a $t$ test.

resistance. Nonsynthetic products, such as the biocontrol agent Bio-Save $10 \mathrm{LP}$ (Pseudomonas syringae Strain ESC10) (Jet Harvest Solutions, Longwood, FL) also are available for commercial use as a postharvest treatment for control of blue mold in apples and pears (6). In general, under commercial conditions, postharvest biocontrol agents alone are not as effective as synthetic fungicides for blue mold control $(4,15)$. A reduced dosage of TBZ in combination with biocontrol agents has shown potential for control of blue mold (4). To minimize fungicide use at packing and
Pathology New Series 0518, Department of Plant Pathology, College of Agricultural, Human, and Natural Resource Sciences Agricultural Research Center, Project No. WNP00367, Washington State University, Pullman, WA 99164-6430, USA.

\section{LITERATURE CITED}

1. Angioni, A., Sarais, G., Dedola, F., and Caboni, P. 2006. Pyrimethanil residues on table grapes Italia after field treatment. J. Environ. Sci. Health [B] 41:833-841.

2. Angioni, A., Schirra, M., Garau, V. L., Melis, M., Tuberoso, C. I. G., and Cabras, P. 2004 Residues of azoxystrobin, fenhexamid and pyrimethanil in strawberry following field treatments and the effect of domestic washing. Food Addit. Contam. 21:1065-1070.

3. Brent, K. J., and Hollomon, D. W. 1998. Fungicide Resistance: The Assessment of Risk FRAC Monogr. No. 2. Global Crop Protection Federation, Brussels, Belgium. pp. 1-48

4. Chand-Goyal, T., and Spotts, R. A. 1996 Control of postharvest pear diseases using natural saprophytic yeast colonists and their combination with a low dosage of thiabendazole. Postharv. Biol. Technol. 7:51-64.

5. Errampalli, D., Brubacher, N. R., and DeEll, J. R. 2006. Sensitivity of Penicillium expansum to diphenylamine and thiabendazole and postharvest control of blue mold with fludioxonil in 'McIntosh' apples. Postharv. Biol. Technol. 39:101-107.

6. Janisiewicz, W. J., and Korsten, L. 2002. Biological control of postharvest diseases of fruits. Annu. Rev. Phytopathol. 40:411-441.

7. Li, H. X., and Xiao, C. L. 2008. Baseline sensitivities to fludioxonil and pyrimethanil in Penicillium expansum populations from apple in Washington State. Postharv. Biol. Technol. 47:239-245.

8. Li, H. X., and Xiao, C. L. 2008. Characterization of fludioxonil-resistant and pyrimethanilresistant phenotypes of Penicillium expansum from apple. Phytopathology 98:427-435.

9. Meheriuk, M. 1993. CA storage conditions for apples, pears, and nashi. Pages 819-841 in: Proc. Int. Controlled Atmos. Res. Conf. 6th Cornell University, Ithaca, NY.

10. Mitcham, E. J., and Mitchell, F. G. 2002 Postharvest handling systems: Pome fruits. Pages 333-344 in: Postharvest Technology of Horticultural Crops. 3rd ed. A. A. Kader, ed. University of California, Agriculture and Natural Resources, Pub. 3311, Oakland, CA.

11. Rosenberger, D. A. 1990. Blue mold. Pages 5455 in: Compendium of Apple and Pear Diseases. A. L. Jones and H. S. Aldwinkle, eds. American Phytopathological Society, St. Paul, MN.

12. Schirra, M., D'Aquino, S., Mulas, M., Melis, R. A. M., Giobbe, S., Migheli, Q., Garau, A. Angioni, A., and Cabras, P. 2008. Efficacy of heat treatments with water and fludioxonil for postharvest control of blue and gray molds on inoculated pears and fludioxonil residues in fruit. J. Food Prot. 71:967-972.

13. Solel, Z., and Edgington, L. V. 1973. Transcuticular movement of fungicides. Phytopathology 63:505-510.

14. Spotts, R. A., and Cervantes, L. A. 1986 Populations, pathogenicity, and benomyl resistance of Botrytis spp., Penicillium spp., and Mucor piriformis in packinghouses. Plant Dis. 70:106-108.

15. Sugar, D., and Spotts, R. A. 1999. Control of postharvest decay in pear by four laboratorygrown yeasts and two registered biocontrol products. Plant Dis. 83:155-158.

16. U.S. Dep. Agric. Foreign Agricultural Services. Pesticide MRL Database. http://www. mrldatabase.com (accessed on 21 March 2009).

17. Xiao, C. L. 2007. Management of fungicide resistance in postharvest pathogens. Proc. Washington State Hortic. Assoc. 102nd Annu. Meeting. pp. 136-139. 